\title{
AS I SEE IT
}

\section{Reconciling utilitarian and non-utilitarian approaches to biodiversity conservation}

\author{
Michel Loreau* \\ Centre for Biodiversity Theory and Modelling, Station d'Ecologie Expérimentale du CNRS, 09200 Moulis, France
}

\begin{abstract}
Two broad types of approaches have been used in biodiversity conservation: (1) nonutilitarian approaches, which put the emphasis on the aesthetic, emotional, spiritual, and ethical values of nature, and (2) utilitarian approaches, which put the emphasis on species and ecosystems as resources or service suppliers for humans. Here, I argue that the long-standing divide between utilitarian and non-utilitarian perspectives is a reflection of the separation between humankind and nature that lies at the root of the global ecological crisis. Neither perspective challenges this separation fundamentally; therefore; neither alone offers a solid foundation for biodiversity conservation. Resolving the current ecological crisis requires, first and foremost, reconciling humans with their own nature, which in turn requires refocusing both human development and nature conservation on fundamental human needs. Contrary to a widely held idea, fundamental human needs do not involve a purely utilitarian or anthropocentric worldview. Quite the opposite, they provide powerful non-utilitarian arguments for nature conservation, and they are fully compatible with the recognition or attribution of intrinsic values in the human and nonhuman world. Human nature is neither fundamentally selfish and utilitarian, nor fundamentally altruistic and non-utilitarian; humans simply have a set of fundamental needs that require satisfaction, and these needs include respecting and loving the world around them.
\end{abstract}

KEY WORDS: Biodiversity conservation $\cdot$ Environmental ethics $\cdot$ Ecological economics $\cdot$ Ecosystem services $\cdot$ Intrinsic value $\cdot$ Instrumental value $\cdot$ Human nature $\cdot$ Fundamental human needs

\section{INTRODUCTION}

The demographic and economic growth of human societies is increasingly colliding with the ecological limits of planet Earth, generating a global ecological crisis. This crisis has multiple facets. It manifests itself in particular by the alteration of global biogeochemical cycles, global climate change, and global biodiversity loss, and these various manifestations are increasingly interconnected. Although scientific and public awareness of the extent of this crisis is growing, action is lagging behind dramatically.

There are many reasons for this dismal state of affairs. It is hard individually to give up the comfort of the modern way of living. It is hard collectively to

\footnotetext{
${ }^{*}$ Corresponding author: michel.loreau@ecoex-moulis.cnrs.fr
}

agree on a fair distribution of efforts, both within and between countries. It is simply hard to change unless we are forced to do so. There are deeper reasons too. The separation between humankind and nature is one of the most powerful founding myths of modern Western civilisation (Loreau 2010). Although this myth does not stand up to any serious scientific scrutiny, it is deeply ingrained in modern philosophy, science, technology, and economy, and it is now sweeping across the globe as a result of the economic success of Western civilisation. Protecting nature thus conflicts implicitly with the modern worldview that humans have the right - indeed, the mission to dominate nature, that human-devised technology is the solution to all problems, and that economic

(C) The author 2014. Open Access under Creative Commons by Attribution Licence. Use, distribution and reproduction are unrestricted. Authors and original publication must be credited. 
growth equals progress. Therefore, whenever nature protection conflicts with economic growth, the economy generally comes first.

Two broad types of arguments have been used to justify the protection of biodiversity, ecosystems, and nature in general. The first type is non-utilitarian, and puts the emphasis on the aesthetic, emotional, spiritual, and ethical values of nature. Individual organisms, species, ecosystems, and even the whole biosphere are viewed as having 'intrinsic values', i.e. as ends in themselves, irrespective of their use by humans. This non-utilitarian approach is the basis of the entire field of environmental ethics, which seeks to derive new ethical principles to govern our attitude towards non-human beings and nature (Taylor 1981, Rolston 1988, Callicott 1995). It has also been prominent in traditional biodiversity conservation movements; the main motivation of many conservationists has been to protect species from extinction irrespective of their possible utilitarian value (Adams 2004).

The second type of argument is utilitarian. The utilitarian approach puts the emphasis on species and ecosystems as resources for humans. These biological resources need to be managed wisely and sustainably to avoid a possible shortage of resources with harmful economic or social consequences. The utilitarian perspective has been prominent in traditional environmental economics and resource management. It is now gaining fast-growing popularity with the new trend towards conservation and management based on ecosystem services. People derive a large number of direct and indirect benefits from ecosystems; these benefits are then conceptualised as 'services' provided by nature to people, by analogy with service provision in economics (Daily 1997, Millennium Ecosystem Assessment 2005). Although the ecosystem service approach is broader than traditional resource management, it shares the same utilitarian perspective, in which biodiversity and ecosystems matter only to the extent that they are a means for human ends.

The tension between the utilitarian and non-utilitarian perspectives is as old as the modern conservation movement itself (Adams 2004), and shows no sign of waning. Non-utilitarians typically criticise utilitarians for being guilty of anthropocentrism and for providing weak arguments for conservation, while utilitarians criticise non-utilitarians for being dogmatic and for lacking pragmatism. This long-standing controversy is detrimental to the protection of biodiversity and ecosystems. Not only does it divide the conservation movement, but, more importantly, it perpetuates confusion on both sides about the genuine objectives and motivations of nature conservation. For instance, the utilitarian ecosystem service approach was largely proposed out of despair at the lack of practical power of non-utilitarian approaches, but its initial proponents nevertheless believe that nature also deserves protection for its own sake (Ehrlich \& Ehrlich 1981). Therefore, moving beyond the divide between traditional utilitarian and non-utilitarian approaches is critical to base the protection of biodiversity and ecosystems on more solid grounds.

My thesis in this essay is 2-fold. First, the opposition between utilitarian and non-utilitarian perspectives is a reflection of the separation between humankind and nature that lies at the root of the current ecological crisis. Neither perspective challenges this separation fundamentally; therefore, neither alone offers a way out of the crisis. Second, to reconcile utilitarian and non-utilitarian perspectives, as well as humankind and nature, requires us to refocus on fundamental human needs, as these are the source of values that motivate both human development and nature conservation. Contrary to a widely held idea, I show that fundamental human needs do not involve a purely utilitarian or anthropocentric worldview; quite the opposite, they provide the most powerful non-utilitarian arguments for nature conservation because they are rooted in human evolutionary history.

\section{SOME LIMITATIONS OF TRADITIONAL UTILITARIAN AND NON-UTILITARIAN APPROACHES}

Environmental ethics has greatly contributed to laying the philosophical foundations of non-utilitarian approaches to nature conservation over the last 40 years. Environmental ethics essentially proposes to extend the traditional boundaries of ethics, which only include humans, to the non-human world. The boundaries of the non-human world included in this new ethics, however, vary greatly depending on the philosophical premises of different authors and schools of thought. For instance, Singer's (1975) extended utilitarianism expands the circle of moral worth only to sentient animals. At the other extreme, Rolston's (1988) broader ecological viewpoint led him to expand this circle not only to all living organisms, but also to species, ecosystems, and the whole biosphere. Since Singer's ethics is both fundamentally utilitarian and unduly restrictive (see, e.g., Rolston 1988 for a critique of ethical approaches based on 
animal suffering), I will regard Rolston's as being more representative of the non-utilitarian approach.

One key concept that underlies Rolston's ethics and environmental ethics in general - is that of the intrinsic value of non-human entities. In contrast to the instrumental value of some entity, which captures its value as a means for the purpose or satisfaction of humans, its intrinsic value represents the value of that entity for its own sake. Traditional human-centred ethics does recognise intrinsic values, but it only attributes them to humans. As Rolston (1988, p. 340) put it, 'Kant knew something about others, but, eminent ethicist though he was, the only others he could see were other humans, others who could say 'I'. Environmental ethics calls for seeing nonhumans, for seeing the biosphere, the Earth, ecosystem communities, fauna, flora, natural kinds that cannot say 'I' but in which there is formed integrity, objective value independent of subjective value'. While most environmental ethicists would agree with Rolston about the need to recognise intrinsic value in non-human others, there has been a long-standing debate in environmental ethics about the source and locus of intrinsic value (Lee 1996), in particular between objectivist standpoints such as Taylor's (1981) and Rolston's (1988), which view intrinsic value as an objective property of the object being valued that exists even in the absence of humans, and subjectivist standpoints such as Callicott's (1995), which view it as a subjective property of the valuing human subject.

As obscure as it might seem to an uninformed outsider, this debate reveals the constant conflict between humans and nature, and between subject and object, that is so central to modernity and that runs through much of environmental ethics without being properly acknowledged and addressed. In this debate, humans are often implicitly placed outside nature, such that the locus of intrinsic value becomes a serious issue. If humans are regarded as an integral part of nature, however-as they really are - the issue loses much relevance. Humans are nodes in a complex web of interactions with the other components of the biosphere; valuation is one aspect of this interaction. The fact that humans value other components subjectively in no way implies that they do so arbitrarily, irrespective of the objective properties of these components, nor does it imply that the latter do not also act as valuing subjects. Objectivists insist on the existence of value relationships between nonhuman living entities as evidence for the objective nature of value, but this argument fails to support moral consideration of these entities, since what is good for them may be bad for humans and other enti- ties (O'Neill 1992). Only those instrumental or intrinsic values that are recognised or attributed by humans can constitute the bases of an environmental ethics because ethics is a human construct. Clearly, any attempt to downplay the role of human subjectivity is doomed to failure. I will discuss later why this conclusion does not necessarily imply any sort of anthropocentrism.

Like traditional modern ethics, environmental ethics also puts much emphasis on rationality. For instance, according to Taylor (1981, p. 202-203), 'when we adopt the attitude of respect for nature as an ultimate moral attitude we make a commitment to live by certain normative principles. (...) the commitment is a moral one because it is understood to be a disinterested matter of principle. It is this feature that distinguishes the attitude of respect for nature from the set of feelings and dispositions that comprise the love of nature. (...) To put it in a Kantian way, to adopt the attitude of respect for nature is to take a stance that one wills it to be a universal law for all rational beings'. There is no doubt that any moral consideration that aspires to universality has to involve rationality, but to disconnect it completely from its emotional bases is a mistake that considerably weakens its effectiveness. There is now compelling evidence from neurosciences, human psychology, and animal psychology, that moral behaviours are driven by emotions and that they also exist in a primitive form in non-human mammals (Damasio 1994, de Waal 2005, Hauser 2006). Humans with damage to the frontal lobes of their brain have intact intellectual and moral competence but abnormal moral performance because they fail to integrate their emotions into their rational deliberations (Damasio 1994, de Waal 2005, Hauser 2006). Thus, although rationality allows emotional responses to be organised in a coherent way, it does not generate morality as such. Therefore, I believe that the emphasis placed by environmental ethics on pure rationality, on 'disinterested matters of principle', on the 'objective' nature of intrinsic value, hinders its potential to act as a guide for action. Emotions and reason cannot be separated from each other.

Utilitarian approaches also invoke rationality, but the scope of this rationality is narrower as it focuses on determining the best way to use limited resources for the satisfaction of human wants or preferences. In contrast to environmental ethics, utilitarian approaches do not address 'disinterested matters of principle'; on the contrary, they use rationality to optimise individual 'interest'. As a result, they look more acceptable in modern society, which by 
and large promotes selfish interests and instrumental rationality. Although traditional utilitarian approaches dealt with specific environmental issues such as economic incentives to reduce pollution or the management of fish stocks, the new ecosystem service framework promoted by the Millennium Ecosystem Assessment (2005) is much more comprehensive and integrative as it encompasses the whole set of effects of ecosystems on human well-being. It even includes the intrinsic value of nature under the category of 'cultural services'. Given its considerable interest as an overarching conceptual framework to address the linkages between ecosystems and human societies, and hence the protection of biodiversity and ecosystems, it is worth considering some of its limitations.

The most significant limitation of the ecosystem service framework is that it is inherently anthropocentric: it assumes that nature revolves around humans and is at their service. That is why, despite its integrative nature, I view it as being fundamentally utilitarian. It is even utilitarian in the narrow economic sense of the term, as reducing nature to a service supplier amounts to absorbing nature in the human economy. Ecological economists do not make a mystery out of it: 'By harnessing recent results on the relationship between biodiversity and ecosystem functioning to an assessment of the valued services that people obtain from the natural environment, the Millennium Ecosystem Assessment has brought the analysis of ecosystems into the domain of economics' (Barbier et al. 2009, p. 248). This shift has some evident potential advantages. In particular, the power of the economic valuation of biodiversity and ecosystems lies in its potential to set the products of nature and those of humankind on an equal footing, and hence to influence the daily behaviour of millions of economic agents in a direction that is more favourable for nature conservation. If biodiversity and ecosystems have economic value, they are more likely to be preserved, either as a worthy source of income or as a means to reduce the costs inherent in environmental degradation.

But reducing nature to a service supplier also conceals considerable dangers. In particular, there will always be the danger that short-term economic imperatives prevail over more fundamental human needs. As Wilson (1992, p. 348) noted, ecosystem 'services are important to human welfare. But they cannot form the whole foundation of an enduring environmental ethic. If a price can be put on something, that something can be devalued, sold, and discarded'. One may even wonder if, by fostering the economic valuation of nature, the ecosystem service framework is not unwittingly preparing the ground for further infringements of economic interests on natural ecosystems. In comparison with these dangers and the high expectations placed in the ecosystem service approach, the economic valuation of ecosystem services has had surprisingly little impact on decision-making so far (Laurans et al. 2013), perhaps because this approach is still too coarse, or because economic valuation plays a more minor role in the decision-making process than assumed by economists.

\section{FUNDAMENTAL HUMAN NEEDS: BEYOND THE DIVIDE BETWEEN INSTRUMENTAL AND INTRINSIC VALUES}

The classic opposition between utilitarian and nonutilitarian approaches, between instrumental and intrinsic values, leads to an apparently unsolvable dilemma: either human subjectivity is the source of value, in which case all values seem to have to be instrumental since the entities to which they apply have value only to the extent that they are means to satisfy human wants or preferences; or intrinsic values are objective properties of entities independent of human subjectivity, in which case they paradoxically fail to justify moral consideration of these entities. What is wrong with this dilemma?

First, this opposition hinges on a sharp separation between subject and object, which itself reflects the modern divide between mind and matter, according to which the subjective belongs to the arbitrary operation of the mind, whereas the objective belongs to the independent properties of matter. As a result, subjectivity is often viewed as the realm of the particular, the personal, the arbitrary, in contrast to objectivity, which is the realm of the universal and the natural. This dualistic worldview ignores the fact that humans think and act as subjects in accordance with a universal biological human nature modulated by culture. Therefore, human subjectivity has an objective, natural, universal dimension.

Second, this opposition also hinges on a sharp separation between the satisfaction of human needs and intrinsic values. This separation results from the widespread assumption that humans and other animals are fundamentally selfish, such that satisfying one's needs implies treating others as instruments of this satisfaction (except when social and moral constraints forbid it). This assumption, which permeates classical economics, rests on a flawed interpretation of evolutionary biology that confounds the process of 
natural selection at the level of the gene and psychological motivation at the level of the organism as a whole. The fact that cooperation and altruism can be favoured by natural selection does not turn them into selfish behaviour. There is now considerable evidence from psychology and neurosciences that empathy is a fundamental feature of human nature that has evolved from the strong sociality of primates (de Waal 2009, Rifkin 2009). Empathy necessarily implies that others (including non-human others) are perceived and valued as ends in themselves, i.e. that they have intrinsic value.

The current global ecological crisis is the historical product of the divorce between humankind and nature that is deeply rooted in modern Western civilisation. Therefore, a reconciliation of humans with their own nature is key to resolving this crisis (Loreau 2010). To recognise the existence of human nature is to acknowledge the fact that humans belong to nature and that they share a set of fundamental needs and values that defines their identity as a species and that makes life together possible beyond individual and cultural differences. Although it is traditionally believed that human needs are potentially infinite and that they are different in each culture and historical period, research in psychology, psychotherapy, and personal development has showed instead that fundamental human needs are finite, few, and universal (Maslow 1987, Max-Neef 1991). What changes through time and among cultures is the way these needs are satisfied. Furthermore, many perceived wants are in fact compensations for unsatisfied fundamental human needs.

One striking feature of the fundamental human needs that have been identified so far is that they extend way beyond the basic physiological or subsistence needs that are traditionally considered. In particular, they include needs for affection, recognition, understanding, and self-fulfilment (Maslow 1987, Max-Neef 1991), which critically hinge upon nonutilitarian interactions with others. Although existing classifications of fundamental human needs do not include a specific need for interactions with the rest of nature, this need is implicit in several others (e.g. understanding, self-fulfilment). A growing body of independent evidence supports the existence of a fundamental human need for interactions with the rest of nature. This need manifests itself positively in the form of 'biophilia', i.e. the connection that humans subconsciously seek with the rest of life as a result of their past evolutionary history (Wilson 1984), and negatively in the form of a 'nature deficit disorder' when it fails to be satisfied (Louv 2005).
Empathy and the existence of fundamental human needs based on non-utilitarian interactions with other human and non-human beings destroy the separation between self-fulfilment and the fulfilment of others, since the fulfilment of others is a condition of my own self-fulfilment, and vice versa. Therefore, the satisfaction of fundamental human needs is not purely self-centred and is fully compatible with the recognition or attribution of intrinsic values in the human and non-human world. In fact, the very distinction between instrumental and intrinsic values becomes blurred and dissolves in a continuum. At one extreme, objects that are appropriated and/or consumed to satisfy basic subsistence and protection needs are clearly endowed with instrumental value since they enter a utilitarian relationship aimed at the preservation or satisfaction of the human user. At the other extreme, human and non-human persons that are respected, honoured, and loved to satisfy affection and self-fulfilment needs are clearly endowed with intrinsic value since their existence as independent subjects is what makes satisfaction of these needs possible.

But many if not all entities are likely to be endowed with a dual instrumental and intrinsic value. For instance, there is no good reason why plant and animal creatures exploited for food or other products should not deserve respect, and hence be also endowed with intrinsic value. Respect for hunted animals is widespread in hunter-gatherer societies, where there is no sharp separation between self and other. Although the individualism of modern society has led to a near-exclusive focus on utility relationships, the respect for non-human creatures is present deep inside each of us and is erased from our consciousness only through systematic educational work during childhood.

The new perspective on human nature provided by the discovery of empathy and fundamental human needs also allows us to move beyond the heated anthropocentrism debate in environmental ethics. Traditional ethics has been accused of anthropocentrism because of its exclusive focus on humans; the alternative perspective was either biocentrism (Taylor 1981) or ecocentrism (Rolston 1988). At first sight, to focus on fundamental human needs and values might seem to bring us straight back to classic anthropocentrism. But this is incorrect. Any ethical or valuation system established by humans rests inevitably on the specific ability of humans to perceive, understand, and value the world. But that world need not be restricted to, or centred on, humans. A purely human world is an illusion created 
by the artificial separation between human spiritual subjects and natural material objects in modern Western civilisation. The satisfaction of fundamental human needs requires us to abandon this illusion and to embrace nature as a whole. Therefore-perhaps counterintuitively - anthropocentrism hinders the full satisfaction of fundamental human needs.

\section{CONCLUSIONS}

Mind versus matter, subject versus object, reason versus emotion, culture versus nature, intrinsic value versus instrumental value: modern Western civilisation has an inordinate fondness for dualism. Unfortunately this dualism does not only exist in our mind; it also manifests itself in the concrete reality of our actions in the world. The current global ecological crisis is the historical product of the divorce between humankind and nature that results from this dualism. Humans are currently destroying biodiversity and ecosystems at unprecedented rates because Western religious and philosophical tradition teaches them that they are different from the rest of nature and that they have the right and the mission to dominate it.

Specific or technical solutions will not be enough to modify the course of history. Although nature and biodiversity conservation has made a difference (the situation would no doubt be worse without it), the more fundamental challenge that human societies are facing today is to destroy the myth of the separation between humans and nature and to consciously reintegrate humans into nature. This challenge requires rethinking almost everything we are accustomed to, from our aims in life to the content and form of the global economy. And yet this formidable challenge is within reach. The first step to meeting this challenge is to listen to our own nature, to our fundamental needs, which speak simply and clearly. Our human nature tells us that we are neither fundamentally selfish and utilitarian, nor fundamentally altruistic and non-utilitarian; we simply have a set of fundamental needs that require satisfaction, and these needs include respecting and loving the world around us.

Acknowledgements. I thank Claire de Mazancourt and Paul Ehrlich for their helpful comments on the manuscript. This work was supported by the TULIP Laboratory of Excellence (ANR-10-LABX-41).

Editorial responsibility: Konstantinos Stergiou, Thessaloniki, Greece

\section{LITERATURE CITED}

Adams WM (2004) Against extinction: the story of conservation. Earthscan, London

Barbier EB, Baumgärtner S, Chopra K, Costello C and others (2009) The valuation of ecosystem services. In: Naeem S, Bunker DE, Hector A, Loreau M, Perrings C (eds) Biodiversity, ecosystem functioning, and human wellbeing: an ecological and economic perspective. Oxford University Press, Oxford, p 248-262

Callicott JB (1995) Intrinsic value in nature: a metaethical analysis. Electronic Journal of Analytic Philosophy 3

Daily GC (ed) (1997) Nature's services: societal dependence on natural ecosystems. Island Press, Washington, DC

Damasio AR (1994) Descartes' error: emotion, reason, and the human brain. G. P. Putnam's Sons, New York, NY

de Waal F (2005) Our inner ape: the best and worst of human nature. Granta Books, London

de Waal F (2009) The age of empathy: nature's lessons for a kinder society. Harmony Books, New York, NY

Ehrlich PR, Ehrlich AH (1981) Extinction: the causes and consequences of the disappearance of species. Random House, New York, NY

Hauser MD (2006) Moral minds: How nature designed our universal sense of right and wrong. Abacus, London

Laurans Y, Rankovic A, Billé R, Pirard R, Mermet L (2013) Use of ecosystem services economic valuation for decision making: questioning a literature blindspot. J Environ Manag 119:208-219

> Lee K (1996) The source and locus of intrinsic value: a reexamination. Environ Ethics 18:297-309

Loreau M (2010) The challenges of biodiversity science. In: Kinne O (ed) Excellence in ecology, Book 17. International Ecology Institute, Oldendorf/Luhe

Louv R (2005) Last child in the woods: saving our children from nature-deficit disorder. Algonquin Books, Chapel Hill, NC

Maslow A (1987) Motivation and personality, 3rd edn. Harper \& Row, New York, NY

Max-Neef M (1991) Human scale development: conception, application and further reflections. The Apex Press, New York, NY

Millennium Ecosystem Assessment (2005) Ecosystems and human well-being: synthesis. Report No. 1559633867 (alk. paper) 1559633875 (pbk.: alk. paper), Island Press, Washington, DC

O'Neill J (1992) The varieties of intrinsic value. Monist 75: $119-137$

Rifkin J (2009) The empathic civilization: the race to global consciousness in a world of crisis. Jeremy P. Tarcher/ Penguin, New York, NY

Rolston HI (1988) Environmental ethics: duties and values in the natural world. Temple University Press, Philadelphia, PA

Singer P (1975) Animal liberation. New York Review Books, New York, NY

Taylor PW (1981) The ethics of respect for nature. Environ Ethics 3:197-218

Wilson EO (1984) Biophilia. Harvard University Press, Cambridge, MA

Wilson EO (1992) The diversity of life. W. W. Norton, New York, NY

Submitted: April 21, 2014; Accepted: May 17, 2014

Proofs received from author(s): July 10, 2014 